\title{
TIPOS BIOQUÍMICOS DE SALMONELLA TYPHI, DE ALGUMAS REGIÕES DO BRASIL
}

\author{
Ernesto Hofer :
}

\begin{abstract}
Foram estudadas 813 amostras de Salmonella typhi provenientes dos estados da Bahia, Guanabara, Pará, Pernambuco e S. Paulo, quanto ao seu comportamento diante da arabinose $e$ xilose.

Revelaram os resultados que 472 culturas $(58,05 \%)$ caracterizaram-se como tipo fermentativo I (acidificando apenas a xilose), 334 amostras (41,08\%) perterceram ao brotipo II (ausência de fermentação em arabinose e xilose), tendo apenas 7 culturas $10,86 \%$, representando o biotipo III ffermentam a arabinose e xilose).
\end{abstract}

A análise dos resultados referentes à ação fermentativa de amostras de Salmonella typhi, em 21 carbohidratos diferentes, pcssibilitou a Jensen (12) em 1901, observar o comportamento irregular desta espécie. no tocante à fermentação da arabinose e xilose.

Mais tarde, estudando esta particularidade, Petersen e Bjornsson (20), sugerem uma classificaçāo das amostras de bacilos tíficos, em très tipos, orientada segundo a produção de ácido na xilose e arabinose. Assim sendo, as cuituras que apenas fermentavam a xilose, foram rotuladas como tipo I; aquelas que eram incapazes de agir sobre estes dois substratos, vieram a caracterizar o tipo II e o tipo III, bem mais rarc, identificado por sua açāo fermentativa sobre a xilose e arabinose.

Kristensen e Henriksen (14) destacam a importância epidemiológica desta classificação para as culturas de $S$. typhi, bem como demonstram a inalterabilidade destes tipos.
As atençōes voltadas sobre este aspecto suscitaram o aparecimento de vários cutros trabalhos, expondo resultados das mais variadas regiōes e oue principalmente vieram confirmar as verificaçõos dos bacteriologistas dinamaroueses.

Ampiiando as pesauisas anteriores, Kristensen (15), lançando mão de grande número de amostras de $S$. typhi, reaviva a importância considerável que representa os dados da classificação bioguímica para as análises epidemiológicas de casos de febre tifóide.

Posteriormente, De Blasi e Buogo (5), estudando o comportamento de 312 amostras de $S$. typhi, tem oportunidade de assinalar a ocorrência de um quarto tipo bioquímicc, apresentando como característica diferencial dos demais, a açào fermentativa apenas sobre a arabinose.

Com a descriçāo da técnica de lisotipia ou fagotipagem $\mathrm{Vi}$ do bacilo tífico, por Craigie e Yen $(3,4)$, houve durante um certo período, o descuramento da classifi-

\footnotetext{
* Departamenio ae Microbiologla e Imunologia do Instituto Oswaldo Cruz. C.P. 926 - Guanabara Recebido para publicaçào em 18.5.1972.
} 
cação bioquimica, $\mathrm{cm}$ vista, do primeiro processo propiciar a caracterização de maior número de tipos da espécie em questão.

Com as verificações de Olitzki e cols. (16), reavivou-se o interesse pela classificaçāo preccnizada por Kristensen, associando-a principalmente a fagotipagem. Outros autcres $(7,8,13,17)$, utilizam e preccnizam o valor desta associação, constituindo-se atualmente, em um fator de extrema importância para a complementação da. lisotipia. Apresenta, principalmente, o mérito de ofertar um maior número de dados, que por consøguinte, possibilitam um melhor critério na avaliação epiłemiológica. da febre tifóide em determinada regiāo. Esta condição se torna ainda mais imprescindivel, quando um numero muito restrito de lisctipos $\mathrm{Vi}$ estejam presentes em uma área endêmica ou epidèmica desta enfermidade.

Embcra se tenha uma elevada prevalência de febre tifóide em nosso meio, contraditoriamente, escassas são as averiguações que se detiveram em relatar a distribuição dos tipos fermentativos de Salmonell typhi mais incidentes, assinalando-se cs trabalhos de Pestana (19), Costa e cols. (2) Penna Costa (18) e Hofer e cols, (9-11).

No presente trabalho, investigou-se o comportamento de amostras de bacilos tificcs, isoladas mais recentemente e oriundas de algumas regiões do Brasil, diante da xilose e arabinose.

\section{MATERIAL E MÉTODOS}

Durante o periodo de 1963 a 1971 , foram analisadas 813 culturas de $S$. typhi, provenientes dos estados da Bahia, Guanabara, Pará, Pernambuco e S. Paulo.

Todas as amcstras foram previamente reisoladas e reidentificadas, do ponto de vista bioquímico e sorológico, adotando-se as técnicas usuais para esta finalidade (6).

Para evidenciar a açāo fermentativa das amostras em estudo, sobre a arabinose e xilose, foi empregado como meio básico, a água peptonada, tendo a seguinte composição:

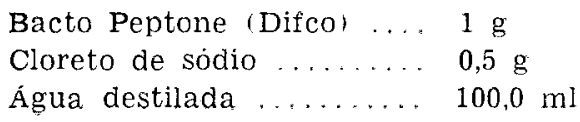

Após ajustar o pH a 7.0, foram acrescentados $1 \mathrm{ml}$ de indicador de Andrade $\mathrm{e}$ em volumes separados do meio, $1 \%$ cios substratos fermentesciveis (Arabinose -. G. T. Gurr e d-Xilcse, Difco). O meio com todos os ingredientes foi esterilizado por filtração em Seitz e distribuido assepticamente em tubos, em volumes de $2 \mathrm{ml}$

Os meios foram semeados com uma alça de $4 \mathrm{~mm}$ de diâmetro de um crescimento de 24 hs a $37^{\circ} \mathrm{C}$, em caldo extrato e a leitura da fermentação foi efetuada, acós incubação a $37^{\circ} \mathrm{C}$ por 24 horas.

\section{RESULTADOS}

As 813 amostras estudadas, revelaram que $472(58,05 \%)$ pertenceram ao tipo $I$, $334(41,08 \%)$ caracterizaram-se no tipo II e apenas 7 culturas foram registradas no tipo III, de acordo com os dados catalogados na Tabela 1 .

Tomando como base as origens das amostras, observa-se que as culturas classificadas no biotipo I predominaram nos estados da Bahia, Pernambuco e Pará, sendo que as do tipo II destacaram-se na Guanabara e S. Paulo.

Convém ainda assinalar a ocorrência do raro tipo III, nas amostras provenientes da Bahia, Guanabara e S. Paulo, assim comc a ausência do biotipo IV, na presente investigação.

\section{DISCUSSÃO}

Atualmente, a investigaçāo epidemiológica com as amostras de $\boldsymbol{S}$. typhi, não se ccncentra apenas nas observações do comportamento bioquimico, particularmente diante da xilose e arabinose. Todas as atenções, neste sentido, estão voltadas, primordialmente para a lisotipia Vi das amostras de bacilos tificos, que oferece maiores recursos para a interpretação dos fenômenos relacionados à epidemiologia da febre tifóide.

Entretanto, com toda a posição de destaque da lisotipia $\mathrm{Vi}$, representando o elemento fundamental para os inquéritos epidemiclógicos, não se poderá olivdar a imfortância da classificação bioquímica, principaimente, após as investigaçōes de Olitz$\mathrm{kj}$ e cols., demonstrando o valor da associação destes dois processos, especialmente 


\section{Tabela I}

Caracterização bioquímica, segundo Kristensen de 813 amostras de S. typhi isoladas em diferentes regicies do Brasil

I

$\mathrm{No}$

Bahia

Guandabra

Fernambuco

136

100

Säo Paulo

Pará

TOTAL

472
39,68

150

II

III

No

60

05

29

82,42

17,57

59,52

2

0,79

0,757

132

TOTAL

261

1.53

165

252

3

813

Tipo I: Xilose + e Arabinose Tipo II: Xilose - e Arabinose -. Tipo III: Xilose + e Arabinose - quando se tem o predominio de um número limitado de tipos fágiccs, em determinada regiãc.

Ccnquanto sejam muito exiguas as referências bibliográficas em nosso meio, (Quadro I) que retrataram este aspecto, ainda assim, possibilitam algumas consideraçóes entre os resultados existentes e cs da presente investigação.

C trabalho pioneiro neste assunto, entre nós, coube a Pestana, obtendo para as 304 amostras isoladas no estado de $\mathrm{S}$. Paulo, acentuada predominância do tipo fermentativo I scbre o biotipc II.

Ainda em relaçāo ao comportamento de culturas oriundas de S. Paulo, tem-se a consignar os achados de costa e cols. revelando uma nítida supremacia do biotipo I.

Comparando estes dados com os atuais, verificamos a inversāo do tipo predominan- te, figurando em primeiro plano, as culturas classificadas no tipo II. Considerando este aspecto divergente, convém assinalar que as nossas amostras, isoladas no período de 1966-1968, representando um total d? 105 culturas, evidenciaram nos resultados, um dcmínio do biotipo I, com freqüência percentual muito aproximada daquela enccntrada por Pestana. Todavia as amostras isoladas na etapa de 1969 a 1971, perfazendo 147 culturas, revelaram na classificaçāo bioquímica, uma maior hegemonia do biotipo II. Esta inversāo foi extraordinariamente influenciada por 50 amostras de bacilos tíficos, provenientes do município de Ribeirão Preto, S. Paulo, que na sua totalidade foram caracterizadas no biotipo II.

Outro pormenor não identificado pelos Autores supracitados, refere-se no pre- 
QUADRO I

Freqüências porcentuais dos tipos bioquímicos de $S$. typhi, observados no Brasil.

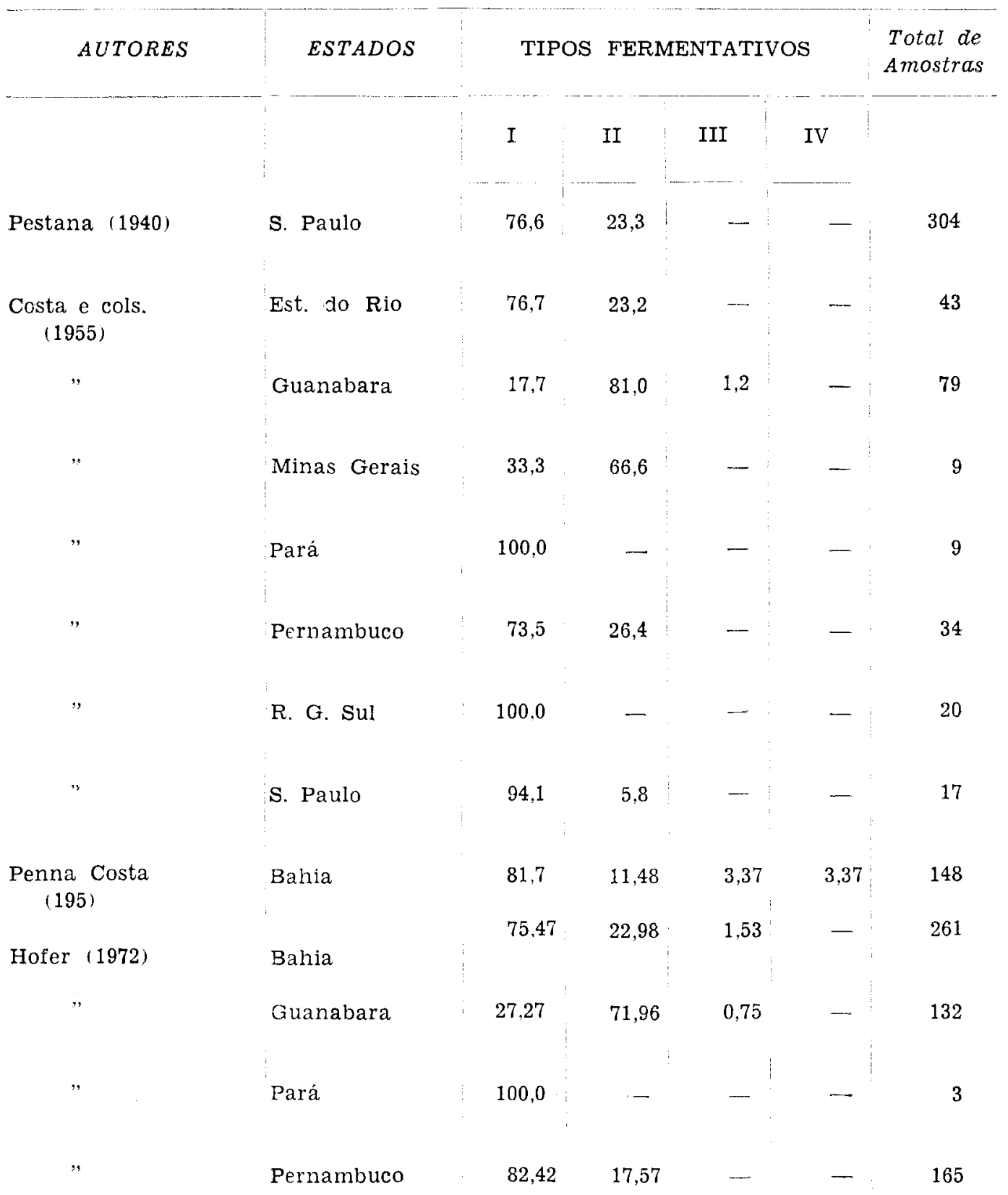
S. Paulo
39,68
59,52
0,79 
sente levantamento, ao aparecimento de amostras do raro biotipo III, em S. Paulo.

Quanto ao confronto das freqüencias percentuais dos tipos fermentativos das culturas oriundas de outras regiōes, estudadas por Costa e cols., em particular naquelas com maior número de amostras, como as dos estados da Guanabara e Pernambuco, observamos um certa simiitude com os achados da presente investigação, assim como uma acentuada concordância dos tipos mais incidentes e suas respectivas frequiências no computo geral.

Finalmente, cabe-nos referir a pesquisa de Penna Costa, realizada com $148 \mathrm{cul-}$ turas isoladas em Salvador, Bahia, tendo a oportunidade de relatar pela primeira vez nosso meio, a corrência do tipo fermentativo IV, além de uma elevada incidência do biotipo III.

Estabelecendo uma comparação com os resultados obtidos por Penna Costa, verifica-se que os nossos dados coadunam-se perfeitamente quanto a predominância de amostras do biotipo I, secundados pelos tipos II e III. Entretanto, não foi possivel nesta oportunidade, evidenciar nas 261 culturas provenientes do estado da Bahia. amostras de $S$. typhi pertencentes ao biotipo IV.

Em conclusão, pode-se admitir que a execução da técnica de lisotipia Vi, esteja reservada, por razóes óbvias, aos chamados laboratórios de referència de um estado ou país, razão pela qual será de extrema utilidade para os inquêritos epidemoilógicos preliminares, a adoção da tipagem bioquímica diante da xilose e arabinose, assim como a pesquisa da tetrationado redutase, relatado anteriormente por Hofer (10), por constituírem técnicas plenamente exequíveis para a maioria dos laboratórios de Saúde Pública.

\section{AGRADECIMENTOS}

Agradecemos ao Sr. Sebastião Januário, pela assistência técnica prestada.

\section{S U M M A R Y}

In the jresent investigation, the author studied the distribution of fermentative types according to Kristensen's Scheme, from 813 cultures of Sallmonella typhi, obtained from the States of Bahia, Guanabara, Pará, Pernnmbuco and $S$. Paulo.

$58,05,41.0^{5}$ and $0,86 \%$ of the strains were classified in fermentative type $I$, 'upe II an inpe III respectivelly. Type IV was not found.

\section{REFERENNCIAS BIBLIOGRÁFICAS}

1. BRANDIS, H. \& MAURER, H. - U̇ber die Beziehungen zwischen Phagentyp und Xyloseverhalten bei Typhusstämmen. Z. Infekt.-Kr., 140: 138-143. 1954.

2. costa, G. A., ALMEIDA, W. A. \& SILVA. - Tipos fermentativos do bacilo tífico. Mem. Inst. Oswaldo Cruz, 53: 115-120, 1955.

3. CRAIGIE, J. \& YEN, C. H. - Demonstration of types of $\mathbf{B}$. typhosus by means of preparations of type II Vi phage. Principles and techniques. Canad. Pub. Health J., 29: 448 463, 1938.
4. CRAIGIE, J. \& YEN, C. H. - Demenstration of types of $\mathbf{B}$. typhosus by means of preparations of type II Vi phage. Stability and Epidemiological significance of $\mathrm{V}$. form type of B. typhosus. Canad. Pub. Health J., 29: 484-496, 1938.

5. DE BLASI, R, \& BUOCO, H. 1952, citado por PAVLATOU, M. \& CINOLLE, F., 1953

6. EDWARDS, P. R. \& EWING, W. H. - Identification of Enterobacteriaceae. and ed. Burgess Publishing Co. Mineneapolis, Minnesota. 258 pag. 1962. 
7. FELIX, A. \& ANDERSON, E. S. Bacteriophage, Virulence and Agglutination tests with a strain of Salmonella typhi of low virulence. J. Hyg.. (London) 49: 349-364, 1951.

8. GIAMMANCO, G. \& CARMENI, A. Caratterizzazione biochimica di lisotipi di S. typhi identification Nell'Ita lia Meridionale en in Sicilia. Nuovi Ann. D'Igi. microbiol, 18: 55-64, 1967

9. HOFER, E. \& VICENTE, M, M. A. Caracterização bioquímica de lisotipos de Salmonella typhi. isoladas no estado da Guanabara. An. Microbiol., (GB), 16: 283, 1969.

10. HOFER, E. \& SILVA, Y P. S. - Pesquisa de tetrationato redutase (TTR) em culturas de Salmonella typhi. Rev. Microbiol., 2: 65-68, 1971.

11. HOFER, E. \& NOVAES, J. R. C. Lisotipos e tipos fermentativos de Salmonella typhi isoladas no estado de S. Paulo. Apresentado no III Congresso Brasileiro de Microbiologia. Belo Horizonte. Minas Gerais. 1971.

12. JENSEN, C. O, 1901, citado por Kristensen, M. \& Henriksen, H. C. D. (1926).

13. JUDE, A. \& NICOLLE, P. - Determination des types bactériophagiques (Vi phage-typing) et caractéres bioquimiques des souches de Salmonella typhi isolées dans les hospitaux militaires de la métropole et de certains territoires de lUnion Française. Ann. Inst. Pateur, 77: 550-506, 1949.

14. KRISTENSEN, $M$ \& HENRIKSEN, H. C. D. - Reactions fermentatives du bacille typhique et leur róle épidémiologique. Acta path. microb. scand., 3: $551-582,1926$.

15. KRISTENSEN, M. - Studies on the type division of the typhoid and pa. ratyphoid $B$ bacilli by fermentations. J. Hyg:, 38: 688, 1938.

16. OLITZKI, L.; OLITZK, Z. SHELÜBSKY, M. - Types of Eberthella typhosa in Palestina. Trans. $R$. Soc Trop. Med. Hyg., 39: 167-174, 1945.

17. PAVLATOU, M. \& NICOLLE, P. Incidence des types biochimiques parmi les types bactériophagiques de Salmonella typhi. Ann. Inst, Pasteur, 25; 185-198, 1953.

18. PENNA COSTA, A. - Contribuição ao estudo epidemiológico da febre tifóide em Salvador (Bahia). Estudo dos tipos bioquímicos do bacilo tífico. Tese para docência-livre de Microbiologia na Faculdade de Medicina da Universidade da Bahia. 1957.

19. PESTANA, B. R. - Tipos e bacilos tíficos e seu valor epidemiológico. An. Paulista Med, Cir., 34:19-25, 1940 .

20. PETERSEN, K. \& BJORNSSON, K, 1909 , citado por Kristensen, M. \& Henriksen, H. C. D. 1926. 